\title{
Metabolic Risk Factors Are Associated With Stiffness Index, Reflection Index and Finger Skin Temperature in Children
}

\section{- Physical Activity and Nutrition in Children (PANIC) Study -}

\author{
Aapo Veijalainen, BSc; Tuomo Tompuri, MD; Tomi Laitinen, MD, PhD; \\ Niina Lintu, BSc; Anna Viitasalo, MD; David E. Laaksonen, MD, PhD; \\ Jarmo Jääskeläinen, MD, PhD; Timo A. Lakka, MD, PhD
}

\begin{abstract}
Background: Childhood metabolic syndrome (MetS) has been found to predict adulthood MetS, type 2 diabetes and cardiovascular disease, emphasizing the early identification of children at increased risk of these diseases. Children with clustering of metabolic risk factors have been reported to have a mild arterial stiffness and endothelial dysfunction, but limited evidence is available from population-based samples of children.
\end{abstract}

\begin{abstract}
Methods and Results: The associations of metabolic risk factors with arterial stiffness, tone and endothelial function were studied in 173 prepubertal children (90 girls) 6-8 years of age. MetS was assessed both by continuous MetScore and dichotomously. Stiffness index (SI), reflection index (RI) and finger skin temperature (FST) were measured before and after maximum exercise test, and percent change was calculated for RI (RI\% $\Delta$ ) and FST $(F S T \% \Delta)$. MetScore $(r=0.26, P=0.001)$, fasting insulin $(r=0.24, P=0.002)$, fasting triglycerides $(r=0.20$, $P=0.009)$, systolic (SBP; $r=0.24, P=0.002)$ and diastolic blood pressure (DBP; $r=0.19, P=0.013)$ correlated with SI. MetScore $(r=-0.17$, $P=0.024, r=0.21, P=0.006)$, waist circumference $(r=-0.19, P=0.012, r=0.23, P=0.003)$ and $S B P(r=-0.16, P=0.035$, $r=0.21, P=0.005)$ correlated with $\mathrm{RI}$ and FST. High-density lipoprotein cholesterol correlated with FST ( $r=-0.22$, $\mathrm{P}=0.004)$ and $\mathrm{FST} \% \Delta(\mathrm{r}=-0.24, \mathrm{P}=0.002)$. RI decreased and FST increased with exercise $(\mathrm{P}<0.001)$. Waist circumference correlated inversely with $R \mid \% \Delta$ in boys $(r=-0.22, P=0.046)$ and directly with $R \mid \% \Delta$ in girls $(r=0.27, P=0.011)$.
\end{abstract}

Conclusions: Metabolic risk factors are associated with arterial stiffness, tone and endothelial function in prepubertal children. (Circ J 2013; 77: 1281-1288)

Key Words: Arterial stiffness; Digital volume pulse; Endothelial function; Finger skin temperature; Pulse contour analysis

$\mathbf{R}$ esearch on the association of adulthood metabolic syndrome (MetS), characterized by a cluster of metabolic and cardiovascular risk factors, including excess body fat, insulin resistance, glucose intolerance, dyslipidemia and elevated blood pressure (BP), with cardiovascular disease has been active. ${ }^{1-3}$ More studies, however, should be targeted at children, in whom the prevalence of overweight and obesity has been rising and the prevention of cardiovascular disease should begin. ${ }^{4-6}$

A cluster of excess body fat, insulin resistance, glucose intolerance, dyslipidemia and elevated BP in children is called pediatric MetS. Children with MetS may also have arterial dysfunction, including arterial wall stiffness and endothelial dysfunction. ${ }^{7-9}$ Identification of pediatric MetS and associated risk factors is important because they have been found to predict adulthood MetS, ${ }^{10,11}$ type 2 diabetes mellitus ${ }^{11}$ and cardiovascular disease. ${ }^{12}$ The definition of pediatric MetS is difficult, because there are no generally accepted criteria for it. ${ }^{13}$ Moreover, the definitions of pediatric MetS have used artificial and arbitrary cut-off points obtained from the definitions of adulthood MetS. Therefore, studies in children have increasingly used metabolic risk scores formed from the Z-scores of the

Received June 4, 2012; revised manuscript received November 3, 2012; accepted December 12, 2012; released online January 25, 2013 Time for primary review: 56 days

Institute of Biomedicine/Physiology, University of Eastern Finland, Kuopio Campus, Kuopio (A.V., T.T., N.L., A.V., D.E.L., T.A.L.); Department of Medicine, Kuopio University Hospital, Kuopio (D.E.L.); Kuopio Research Institute of Exercise Medicine, Kuopio (T.A.L.); and Department of Clinical Physiology and Nuclear Medicine (T.T., T.L.), Department of Pediatrics (J.J.), Kuopio University Hospital and University of Eastern Finland, Kuopio Campus, Kuopio, Finland

Mailing address: Aapo Veijalainen/PANIC-Study, BSc, Institute of Biomedicine/Physiology, University of Eastern Finland, Kuopio Campus, PO Box 1627 FI-70211 Kuopio, Finland. E-mail: veijalai@ student.uef.fi

ISSN-1346-9843 doi:10.1253/circj.CJ-12-0704

All rights are reserved to the Japanese Circulation Society. For permissions, please e-mail: cj@j-circ.or.jp 
core features of MetS. ${ }^{14,15}$

Pulse contour analysis (PCA) is an easy and non-invasive method that provides useful indices of arterial function and health, such as the stiffness index (SI) and the reflection index (RI). SI has been shown to have a strong positive correlation with pulse wave velocity between the carotid and femoral artery, the standard for measuring arterial stiffness. ${ }^{16} \mathrm{RI}$ reflects arterial tone, and change in RI induced by vasoactive drugs has been associated with flow-mediated dilation (FMD), the standard for measuring endothelial function. ${ }^{16-19}$ Another simple measure of arterial function is change in finger skin temperature (FST) in a reactive hyperemia. ${ }^{20}$

There are few studies on the associations of MetS and its components with arterial wall stiffness and endothelial dysfunction in children. SI as measured by PCA was recently found to be higher in children and adolescents with MetS and its components, including higher waist circumference (WC), fasting plasma glucose, BP and plasma triglycerides and lower highdensity lipoprotein cholesterol (HDL-C) in Chinese children and adolescents. ${ }^{21}$ No findings on RI, however, have been reported.

A single bout of exercise has been found to dilate skeletal muscle arteries, reduce pressure wave reflection and change the morphology of the radial and digital artery pressure pulse wave in a similar way to nitrovasodilators. ${ }^{22}$ Little is known, however, about the acute effects of exercise on SI, RI and FST. We recently found that a single bout of exercise had no effect on SI, but it lowered the amplitude of the reflected wave and thus RI, and increased FST, which could support their use as measures of arterial endothelial function and exercise-induced hyperemia. ${ }^{23}$

The aim of the present study was to investigate the associations of the main features of MetS with SI and RI, measured by PCA, as well as FST at rest and in response to a single bout of exercise in a population-based sample of Finnish prepubertal children 6-8 years of age.

\section{Methods}

\section{Subjects}

The original subject group was a representative populationbased sample of 512 children 6-8 years of age from the city of Kuopio in Eastern Finland who participated in the baseline examinations of the Physical Activity and Nutrition in Children (PANIC) Study between October 2007 and December 2009. PCA analysis has been done for 230 children since autumn 2008, when we received the PCA device. Due to unrepresentative waveforms in PCA or incomplete FST data before or after the exercise test, the number of children was reduced to 175 . After further exclusion of children with clinical signs of puberty (Tanner stage $\mathrm{G} / \mathrm{B} \geq 2$ ), complete data on PCA and FST analysis were available in 173 children ( 90 girls, 83 boys), who were included in the present study. There were no statistically significant differences in clinical characteristics between the included and excluded children. All children were examined by a physician. The study protocol was approved by the Research Ethics Committee of the Hospital District of Northern Savo (Kuopio, Finland). All children and their parents gave their informed written consent.

\section{Assessment of SI, RI, Heart Rate and FST}

SI, RI, heart rate and FST were assessed and the exercise tests were done in an exercise test laboratory with a stable temperature $\left(20-22^{\circ} \mathrm{C}\right)$. PCA is based on non-invasive photoplethysmography and has been explained in more detail previ- ously. ${ }^{23}$ Briefly, SI is calculated as body height ( $\mathrm{m}$ ) divided by time between the first (systolic) peak and the second (diastolic) peak of the pulse contour (s), and RI is calculated as the height of the second peak divided by the height of the first peak, expressed as percentage.

PCA was performed after rest in a supine position before and after the exercise test with the PulseTrace PCA2 device (Micro Medical, Gillingham, Kent, UK) as reported previously. ${ }^{23}$ All pulse contours were visually examined afterwards to control for quality. Data were not accepted for analysis if there was an extra peak between the systolic and diastolic peak that was incorrectly defined as the diastolic peak; if the PCA indexes were incorrectly measured by the device; or if the pulse contours of the same child markedly differed visually. Heart rate was also assessed with the PCA device.

The within-subject coefficient of variation (CV) was $7.4 \%$ for SI and $12.2 \%$ for RI before the exercise test, and $5.3 \%$ for SI and $19.6 \%$ for RI after the exercise test. Inter-observer variability is not presented because of automatic measurement. We have previously found in 6-8-year-old children a relatively good reproducibility for $\mathrm{SI}$ before the exercise test (intra-class correlation coefficient [ICC], 0.44; CV, 6.3\%), but a worse reproducibility for RI (ICC, $0.42 ; \mathrm{CV}, 18.7 \%$ ), probably because RI depends on vascular tone, which varies greatly over time. ${ }^{23}$

Finger pulp consists mainly of arteriovenous anastomoses, ${ }^{24}$ and FST reflects thermoregulation. Both ambient temperature and body core temperature physiologically affect blood flow and skin temperature mainly via sympathetic nervous system regulation. ${ }^{25}$ As a thermoregulatory response, skin blood flow increases when core temperature rises during exercise. ${ }^{26}$ The endothelium plays an important role in the regulation of skin blood flow and thermoregulation by changing the vascular tone. ${ }^{27}$

Before PCA, FST was measured 3 times from the tip of the left middle finger with an infra-red thermometer to an accuracy of $0.1^{\circ} \mathrm{C}$ (Thermofocus 01500/A3; Technimed, Varese, Italy). The within-subject CV was $1.0 \%$ for FST before the exercise test and $0.9 \%$ for FST after the exercise test. Interobserver variability is not presented because of automatic measurement. We have earlier found a relatively good reproducibility for FST before the exercise test (ICC, 0.50; CV, $10.0 \%){ }^{23}$

\section{Exercise Testing}

The exercise tests were done using an electromagnetic cycle ergometer that was controlled by Cardiosoft (V6.5 GE Healthcare Medical Systems, Freiburg, Germany) and had a pediatric saddle (Ergoselect 200K, Ergoline, Germany). The exercise testing protocol has been described in detail previously. ${ }^{23}$ Briefly, there was a progressive $1-\mathrm{W}$ increase in workload every 6 s until exhaustion.

\section{Assessment of MetS Components}

Body height and weight, body mass index (BMI) and WC were assessed as reported in detail elsewhere. ${ }^{28}$ Standard deviation scores were calculated using a calculator based on data derived from samples of children in the UK. ${ }^{29}$

Also measurements of insulin, glucose, triglycerides, HDL-C and systolic (SBP) and diastolic BP (DBP) were reported previously. ${ }^{28}$ In this study, however, when BP was used as a confounding factor for the associations of SI, the measurement just before the exercise test in the supine position was used to standardize the hemodynamic state.

\section{Definition of MetS}

Primarily, we defined MetS by using a continuous MetS score 


\begin{tabular}{|c|c|c|c|c|}
\hline & Definition & n (\%) & Definition & n (\%) \\
\hline & $\begin{array}{l}\text { Modified NCEP } \\
(\geq 3 / 5 \text { comp.) }\end{array}$ & $35(20.2)$ & Pediatric NCEP ( $\geq 3 / 5$ comp.) & $3(1.7)$ \\
\hline & $\begin{array}{l}\text { Modified IDF } \\
\text { (Overweight }+\geq 2 \text { comp.) }\end{array}$ & $25(14.5)$ & Pediatric IDF (Overweight $+\geq 2$ comp.) & $3(1.7)$ \\
\hline Overweight & & $49(28.3)$ & & $18(10.4)$ \\
\hline BMI & $\geq 75^{\text {th }}$ percentile $^{\dagger}$ & $43(24.9)$ & According to Cole classification ${ }^{37}$ & $18(10.4)$ \\
\hline WC & $\geq 75^{\text {th }}$ percentile $^{\dagger}$ & $41(23.7)$ & $\begin{array}{l}\text { Age- and gender-specified cut-points } \\
\text { based on adult definitions }{ }^{38}\end{array}$ & $4(2.3)$ \\
\hline HDL-C & $\leq 25^{\text {th }}$ percentile $^{\dagger}$ & $40(23.1)$ & $\begin{array}{l}\text { Age- and gender-specified cut-points } \\
\text { based on adult definitions }{ }^{38}\end{array}$ & $23(13.3)$ \\
\hline TG & $\geq 75^{\text {th }}$ percentile $^{\dagger}$ & $46(26.6)$ & $\begin{array}{l}\text { Age- and gender-specified cut-points } \\
\text { based on adult definitions }{ }^{38}\end{array}$ & $4(2.3)$ \\
\hline Glucose & $\geq 75^{\text {th }}$ percentile $^{\dagger}$ & $64(37)$ & $\geq 5.6 \mathrm{mmol} / \mathrm{L}$ & $6(3.5)$ \\
\hline SBP or DBP & $\geq 75^{\text {th }}$ percentile $^{\dagger}$ & $74(42.8)$ & $\geq 90^{\text {th }}$ percentile according to NHBPEP ${ }^{39}$ & $29(16.8)$ \\
\hline
\end{tabular}

†Age- and gender-specified cut points from all 512 children of the PANIC Study.

$\mathrm{BMI}$, body mass index; comp, components; DBP, diastolic blood pressure; HDL-C, high-density lipoprotein cholesterol; IDF, International Diabetes Federation; MetS, metabolic syndrome; NCEP, National Cholesterol Education Program; NHBPEP, National High Blood Pressure Education Program; SBP, systolic blood pressure; TG, triglycerides; WC, waist circumference.

\begin{tabular}{|lccc|}
\hline Table 2. Clinical Characteristics & & & \\
& All children $(\mathbf{n = 1 7 3})$ & Boys $(\mathbf{n}=\mathbf{8 3})$ & Girls $(\mathbf{n}=90)$ \\
Age (years) & $7.7(0.4 \mid 2.2)$ & $7.7(0.4 \mid 2.2)$ & $7.6(0.4 \mid 1.5)$ \\
Body height (cm) & $129(5.1 \mid 28.7)$ & $130.3(4.5 \mid 23.8)$ & $127.9(5.4 \mid 28.7)$ \\
Body height SDS & $0.7(0.9 \mid 4.9)$ & $0.8(0.8 \mid 4)$ & $0.6(0.9 \mid 4.9)$ \\
Body weight (kg) & $26.9(4.3 \mid 23.9)$ & $27.5(4.3 \mid 21.6)$ & $26.3(4.2 \mid 23.9)$ \\
Body weight SDS & $0.4(0.9 \mid 4.8)$ & $0.5(1 \mid 4.5)$ & $0.3(0.9 \mid 4.7)$ \\
BMI (kg/m²) & $16.1(1.9 \mid 10.1)$ & $16.1(1.9 \mid 10)$ & $16.0(1.9 \mid 9.2)$ \\
BMI SDS & $0(1 \mid 5.3)$ & $0.1(1.1 \mid 5.3)$ & $0(0.9 \mid 4.6)$ \\
WC (cm) & $56.4(5 \mid 33)$ & $57.3(4.8 \mid 27.9)$ & $55.6(5.1 \mid 33)$ \\
HDL-C (mmol/L) & $1.6(0.3 \mid 2)$ & $1.7(0.3 \mid 1.4)$ & $1.6(0.3 \mid 2)$ \\
TG (mmol/L) & $0.6(0.3 \mid 1.4)$ & $0.6(0.3 \mid 1.4)$ & $0.6(0.2 \mid 1.3)$ \\
Glucose (mmol/L) & $4.9(0.4 \mid 3.2)$ & $4.9(0.4 \mid 3.2)$ & $4.8(0.4 \mid 2.5)$ \\
Insulin (mU/L) & $4.7(2.4 \mid 12.7)$ & $4.5(2.2 \mid 12)$ & $4.9(2.5 \mid 12.5)$ \\
SBP (mmHg) & $100.2(7.0 \mid 40.7)$ & $100.9(6.9 \mid 40)$ & $99.5(7.0 \mid 34.7)$ \\
DBP (mmHg) & $61.7(7.3 \mid 42.7)$ & $62.1(8.2 \mid 42.7)$ & $61.3(6.4 \mid 34.7)$ \\
MetS score & $0.01(3.4 \mid 20.4)$ & $0.2(3.3 \mid 15.2)$ & $-0.2(3.5 \mid 20.4)$ \\
\hline
\end{tabular}

Data given as means, SD and differences between the highest and lowest values, expressed as mean (SD | range). All biochemical analyses were done from fasting plasma samples, except insulin from fasting serum samples.

SDS, standard deviation score. Other abbreviations as in Table 1.

variable. Especially in children, there is no clear rationale for the dichotomous assessment of MetS or its components, because metabolic risk factors and their clustering increase in a graded fashion; there is no widely accepted definition; and proposed definitions have a low prevalence. Use of a continuous risk score also increases statistical power and is less error prone as compared to dichotomous assessment. ${ }^{30-34}$ Furthermore the continuous method was recently validated in 7-9-yearold children. ${ }^{35}$ The metabolic score has been defined in various ways including the key elements of MetS. ${ }^{36} \mathrm{We}$ calculated the MetS score as reported previously ${ }^{28}$ using Z-scores of the following variables with the following formula: $\mathrm{WC}+$ insulin + glucose-HDL-C + triglycerides + average of SBP and DBP. It was highly correlated $(\mathrm{r}=0.97, \mathrm{P}<0.001)$ and the reported values were nearly identical with a score previously validated by another group ${ }^{35}$ that included the homeostasis model assessment instead of insulin and glucose, and mean arterial pressure as the BP component.

In contrast we also defined MetS with multiple dichotomous assessments (Table 1), as reported previously in Finnish children, ${ }^{10}$ but we defined overweight with either WC or BMI greater than the cut-off. Cut-offs for the modified National Education Cholesterol Program (modNCEP) and modified International Diabetes Federation (modIDF) were calculated from the original study population $(n=512)$ gender- and agespecifically, and previously reported values ${ }^{37-39}$ were used for pediatric NCEP (pedNCEP) and pediatric IDF (pedIDF) as demonstrated in Table 1.

\section{Statistical Analysis}

Normality of distributions of variables was tested with the Kolmogorov-Smirnov test and visually from histograms. Logarithmic or square root transformation was used before analysis for variables that were not distributed normally. Differences 

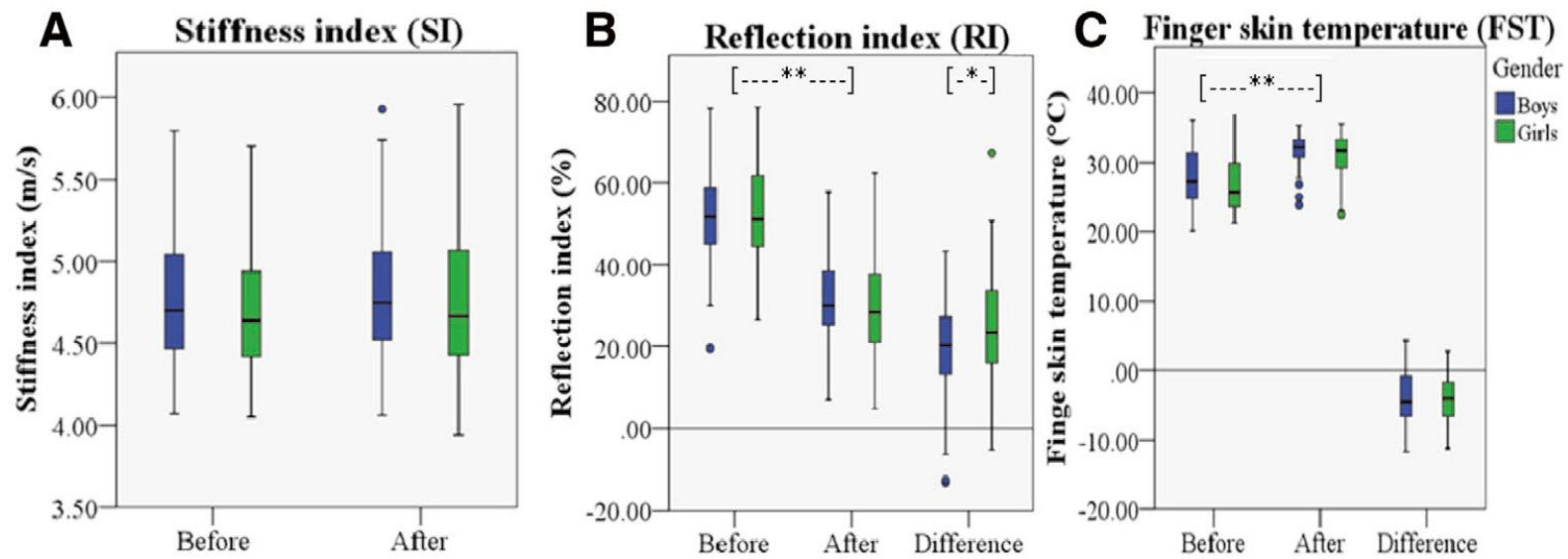

Figure 1. (A) Stiffness index (SI), (B) reflection index (RI) and (C) finger skin temperature (FST) before and after exercise test. A statistically significant exercise-induced change in RI and FST was seen in both genders $\left({ }^{\star *} P<0.001\right)$, but the change in RI was statistically significantly smaller in boys ( $\left.{ }^{*} \mathrm{P}=0.043\right)$. Upper margin of box, $75^{\text {th }}$ percentile; lower margin, $25^{\text {th }}$ percentile; line in middle, median; whiskers, highest and lowest data points (respectively) that are not outliers (>1.5-fold the interquartile range; represented by circles).

\begin{tabular}{|lccccccccc}
\hline \multicolumn{2}{l}{ Table 3. Partial Correlation Coefficients After Adjustment for Gender and Age } & & & \\
& MetS score & Waist & Insulin & Glucose & TG & HDL-C & SBP & DBP \\
SI & 0.258 & 0.068 & 0.238 & 0.080 & 0.199 & -0.042 & 0.235 & 0.190 \\
& $(0.001)^{*}$ & $(0.379)$ & $(0.002)^{*}$ & $(0.299)$ & $(0.009)^{*}$ & $(0.583)$ & $(0.002)^{*}$ & $(0.013)^{*}$ \\
RI & -0.173 & -0.191 & -0.077 & -0.065 & 0.053 & 0.139 & -0.161 & -0.123 \\
& $(0.024)^{*}$ & $(0.012)^{*}$ & $(0.320)$ & $(0.397)$ & $(0.495)$ & $(0.070)$ & $(0.035)^{*}$ & $(0.111)$ \\
FST & 0.209 & 0.228 & -0.034 & 0.079 & 0.033 & -0.223 & 0.212 & 0.099 \\
& $(0.006)^{*}$ & $(0.003)^{*}$ & $(0.662)$ & $(0.308)$ & $(0.672)$ & $(0.004)^{*}$ & $(0.005)^{*}$ & $(0.199)$ \\
RI $\Delta$ & -0.067 & -0.050 & -0.086 & -0.051 & 0.060 & 0.029 & -0.062 & -0.063 \\
& $(0.383)$ & $(0.513)$ & $(0.267)$ & $(0.508)$ & $(0.439)$ & $(0.712)$ & $(0.422)$ & $(0.412)$ \\
RI\% $\Delta$ & -0.002 & 0.015 & -0.037 & -0.018 & 0.046 & -0.013 & -0.017 & -0.027 \\
& $(0.980)$ & $(0.842)$ & $(0.632)$ & $(0.814)$ & $(0.556)$ & $(0.866)$ & $(0.828)$ & $(0.726)$ \\
FST $\Delta$ & 0.112 & 0.096 & -0.066 & 0.059 & 0.028 & -0.205 & 0.022 & 0.077 \\
& $(0.147)$ & $(0.210)$ & $(0.390)$ & $(0.448)$ & $(0.717)$ & $(0.007)^{*}$ & $(0.775)$ & $(0.320)$ \\
FST\% $\Delta$ & 0.140 & 0.114 & -0.065 & 0.061 & 0.038 & -0.241 & 0.054 & 0.095 \\
& $(0.068)$ & $(0.138)$ & $(0.400)$ & $(0.430)$ & $(0.623)$ & $(0.002)^{*}$ & $(0.486)$ & $(0.220)$ \\
\hline
\end{tabular}

Data given as partial correlation coefficients (P-value). ${ }^{*} \mathrm{P}<0.05$.

$\Delta$, exercise-induced change (before-after); FST, finger skin temperature; \% $\%$, percentage exercise-induced change from baseline; RI, reflection index; SI, stiffness index. Other abbreviations as in Table 1.

in means of the variables assessed before and after the exercise test were analyzed with the paired samples t-test. Differences in the means between genders and dichotomized groups of components of MetS from different definitions (Table 1) were analyzed with the independent samples t-test. If the means differed statistically significantly between genders, we tested whether gender modified the associations of interest by entering a product of the variables in general linear models. Individual responses of RI and FST to exercise are presented as the absolute (RI $\Delta$ and FST $\Delta$ ) and percentage change (RI $\Delta \%$ and FST $\Delta \%$ ) from baseline (before-after). The associations of MetS score and its components with continuous SI, RI and FST variables were analyzed with linear regression models by forcing covariates into the models. Possible collinearity of the variables was tested with Pearson's coefficients for correla- tion. Highly intercorrelated variables were not forced into the same models, in order to avoid problems with collinearity. Differences in means of SI across quartiles of MetS score and insulin levels were analyzed with general linear models. All analyses were done with SPSS Statistics 19.0 (IBM Corp, Armonk, NY, USA).

\section{Results}

The number of children having MetS and its separate components are given in Table 1. Clinical characteristics are listed in Table 2. As presented in Figure 1, the means of SI, RI and FST were similar in boys and girls before and after the exercise test. RI decreased substantially and FST increased in response to exercise among boys and girls $(\mathrm{P}<0.001)$. The de- 

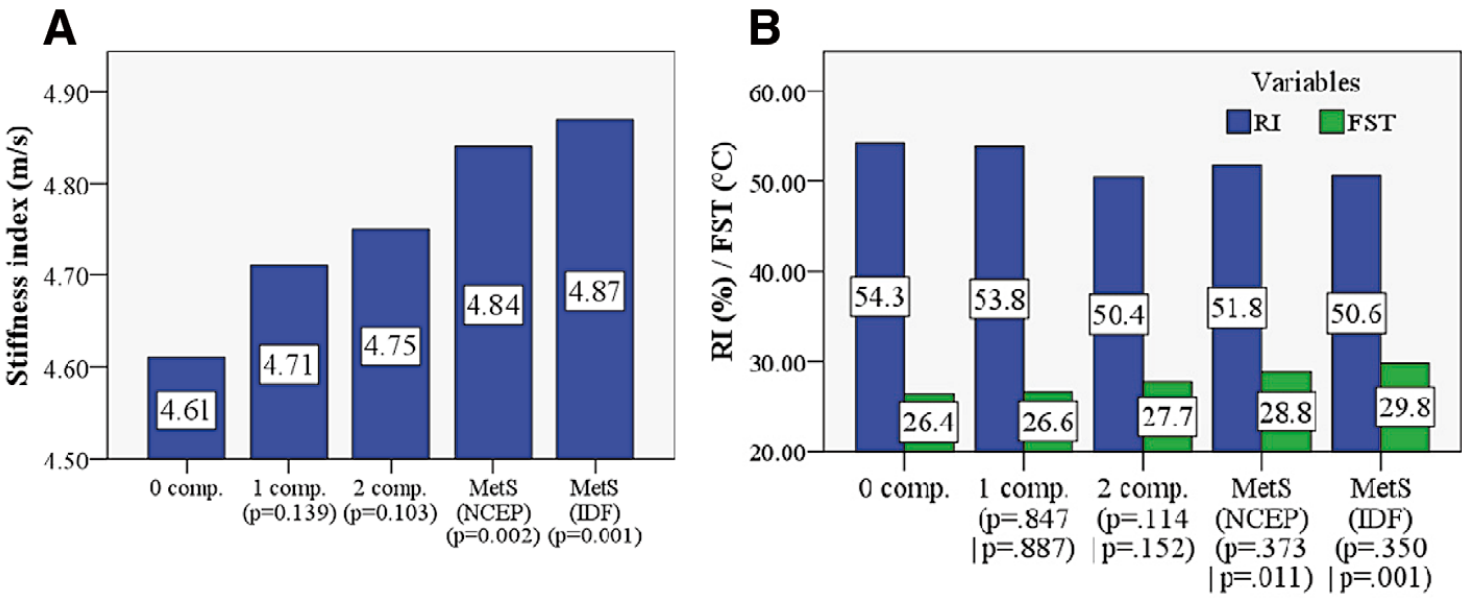

Figure 2. Means of $(\mathbf{A})$ stiffness index $(\mathrm{SI})$ and $(\mathbf{B})$ reflection index $(\mathrm{RI})$ and finger skin temperature (FST) in groups of clustering of components (comp.) of metabolic syndrome (MetS) according to modified definitions. P-value, compared to those having no features of MetS. IDF, International Diabetes Federation; NCEP, National Education Cholesterol Program.

crease in $\mathrm{RI}$ in response to exercise was greater among girls than boys $(\mathrm{P}=0.043)$. FST and $\mathrm{RI}$ at rest $(\mathrm{r}=-0.393, \mathrm{P}<0.001)$ and their responses to acute exercise $(\mathrm{r}=-0.239, \mathrm{P}=0.002)$ significantly correlated with each other, whereas FST and SI $(\mathrm{r}=-0.061, \mathrm{P}=0.425)$ and $\mathrm{RI}$ and $\mathrm{SI}(\mathrm{r}=0.148, \mathrm{P}=0.053)$ at rest had no significant intercorrelations.

MetS score was positively correlated with SI and FST and negatively correlated with RI (Table 3 ). WC was positively correlated with FST but negatively correlated with RI. Insulin and triglycerides were positively correlated with SI. HDL cholesterol was negatively correlated with FST. SBP was positively correlated with SI and FST but negatively with RI. Also DBP was positively correlated with SI. Corresponding findings using dichotomous variables are presented in Figure 2 or Figures S1-S3.

MetS score and its components showed no statistically significant correlations with $\mathrm{RI} \Delta$ and $\mathrm{RI} \Delta \%$ among boys and girls combined (Table 3), but gender modified the associations of WC with $\mathrm{RI} \Delta$ and $\mathrm{RI} \Delta \%(\mathrm{P}=0.008$ and 0.002 for interactions) together with SBP and RI $\Delta$ and RI $\Delta \%(\mathrm{P}=0.048$ and $<0.001)$. $\mathrm{WC}$ and SBP had negative correlations with RI $\Delta(\mathrm{r}=-0.244$, $\mathrm{P}=0.026$ and $\mathrm{r}=-0.208, \mathrm{P}=0.060)$ and $\mathrm{RI} \Delta \%(\mathrm{r}=-0.220, \mathrm{P}=0.046$ and $\mathrm{r}=0.287, \mathrm{P}=0.008)$ in boys and positive correlations in girls (RI $\Delta$ : $\mathrm{r}=0.167, \mathrm{P}=0.115$ and $\mathrm{r}=0.101, \mathrm{P}=0.343$; $\mathrm{RI} \Delta \%$ : $\mathrm{r}=0.266, \mathrm{P}=0.011$ and $\mathrm{r}=0.254, \mathrm{P}=0.016$ ), although $\mathrm{RI} \Delta$ lacked statistic significance with SBP and WC in girls. Gender also modified the association of MetS score with $\mathrm{RI} \Delta \%(\mathrm{P}=0.012)$, and MetS score had significant correlation with $\mathrm{RI} \Delta \%$ among girls $(\mathrm{r}=0.209, \mathrm{P}=0.049)$ but not in boys $(\mathrm{r}=-0.179, \mathrm{P}=0.105)$. Corresponding findings using dichotomous variables are presented in Table S1.

HDL-C correlated negatively with FST $\Delta$ and FST $\Delta \%$ among boys and girls combined (Table 3 ). Corresponding findings using dichotomous variables are presented in Table $\mathbf{S 1}$.

MetS score (standardized regression coefficient $\mathrm{B}=0.230$, $\mathrm{P}=0.001)$, insulin $(\mathrm{B}=0.213, \mathrm{P}=0.003)$ and triglycerides $(\mathrm{B}=0.171, \mathrm{P}=0.016)$ remained statistically significant determinants of SI even after adjustment for age, gender, heart rate and SBP measured just before exercise. SBP, however, was

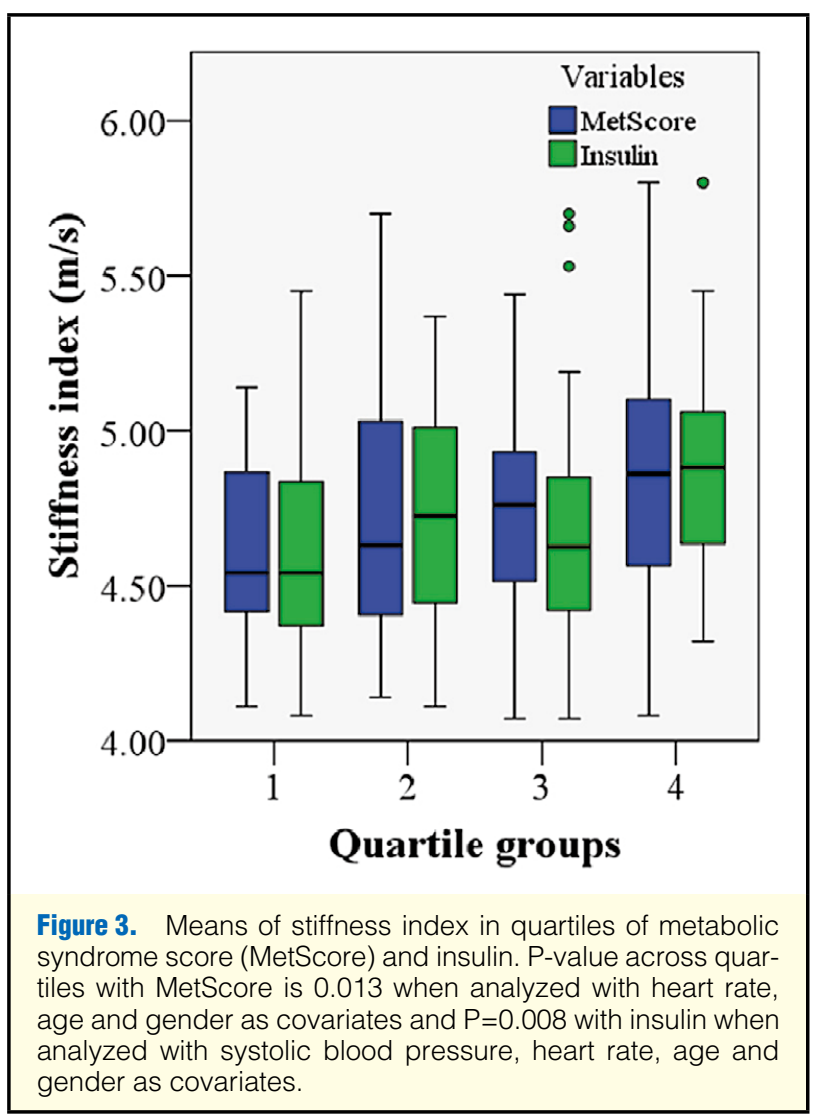

not adjusted in analysis of MetS score to avoid overadjustment. The means of SI increased statistically significantly with increasing quartiles of MetS score and insulin adjusting for age, gender, heart rate and SBP (SBP was not included with analysis of MetS score; Figure 3). 


\section{Discussion}

The present results of this study in a population-based sample of prepubertal children suggest that MetS and some of its components are associated with measures of arterial stiffness, tone and endothelial function at rest already in prepubertal children. The present findings also suggest that RI decreases and FST increases in response to exercise until exhaustion, but that these exercise-induced changes in RI and FST are not consistently associated with MetS and its components.

The prevalence of MetS in children varies markedly depending on definitions used. ${ }^{40}$ The prevalence of the MetS in this study was similar to that in Young Finns study. ${ }^{10}$

MetS score, insulin and triglycerides were directly associated with SI, even after controlling for confounding factors. Also SBP and DBP were associated with higher SI. Similarly with dichotomous variables, SI was significantly higher when MetS was present according to all definitions used. SI was also higher for individual risk factors, but significantly only in those with high triglycerides and BP. These observations suggest that higher levels of metabolic risk factors may increase arterial stiffness already in prepubertal children. The present findings provide further support for the observations of another study in Chinese children and adolescents with a broad age range of 6-18 years. ${ }^{21}$ The Chinese research group, however, did not report their results for the prepubertal children separately. The present study agrees with findings on BP in another study. ${ }^{41}$

$\mathrm{RI}$ at rest reflects the current state of arterial tone, ${ }^{16,17}$ and a lower RI is an indicator of more relaxed arteries. Also FST reflects blood flow ${ }^{42,43}$ and is regulated by sympathetic tone, ${ }^{44}$ which relates FST to RI and endothelial function, ${ }^{45}$ but not to SI. ${ }^{16,17}$ Thus, a higher FST is also a marker of more open peripheral blood flow. The present data suggest that children with a larger WC and a higher MetS score have a paradoxically lower arterial tone, as indicated by a lower RI and a higher FST at rest. The findings were mainly similar when using dichotomized variables. The explanations for these findings are unclear, although it is likely that a more closed periphery has a larger capacity for vasodilation than a more open periphery. Previous studies have generally assessed RI and FST in response to stimuli, such as vasoactive drugs or cold or heat exposure and have mainly included a fairly small number of adults. Regulation of arterial tone is complex, involving adjustments of balance of neuronal, humoral and mechanical factors related to autoregulation of blood flow and BP as well as thermoregulation. ${ }^{46-52}$ The present findings suggest, however, that abdominal fat accumulation and overall metabolic risk among children is associated with decreased arterial tone at rest, as measured by RI and FST. Further studies of the main physiological mechanisms regulating RI and FST at rest are warranted.

As would be expected, FST was negatively correlated with RI but not with SI. Most features of MetS were correlated with FST in the opposite direction as with RI and these findings were mainly similar using dichotomous variables. HDL-C, however, was inversely associated with FST, but had no statistically significant association with SI or RI.

The exercise-induced change in RI could reflect the shear stress-induced release of nitric oxide from endothelial cells, as seen in the pressure pulse waveform measured from the finger after the exercise test. The observed effect of acute exercise was similar to the effect of nitroglycerin, ${ }^{22}$ in which a larger change in RI demonstrates stronger vascular reactivity. A single bout of exercise has been shown to increase nitric oxide synthase activity and thereby cause arterial dilation. ${ }^{53}$ Moreover, the inhibition of nitric oxide synthase activity has been observed to reduce exercise-induced vasodilatation. ${ }^{54}$ The studies on PCA and the effects of acute exercise are limited. ${ }^{23}$ Studies done with FMD report no clear settings for optimal timing or either exercise intensity or type of exercise to investigate endothelial function. ${ }^{55}$ Also the intensity of exercise has been reported to affect the findings, so that the moderate-intensity exercise induces vasodilation through an increase in nitric oxide bioavailability whereas high-intensity exercise increases oxidative stress. ${ }^{56}$ In the current study the intensity of exercise rose gradually. Thus the definite mechanism influencing changes in RI and FST cannot be identified, but it is likely to be due in part to shear stress-induced changes in endothelial function.

Most features of MetS had no statistically significant associations with the exercise-induced change in RI, but gender modified the association of WC and SBP with exercise-induced change in RI so that higher WC and SBP were associated with a smaller exercise-induced change in RI among boys and, paradoxically, with a larger change among girls. A higher MetS score was also associated with a higher change in RI among girls, whereas the association was inverse in boys but statistically non-significant. Also, findings in dichotomous variables mainly agreed with those with continuous variables, but obese and insulin-resistant individuals have consistently had impaired endothelial function, as assessed using several approaches. $9,57,58$ Although the children in the present study were prepubertal, there are endocrinological differences between girls and boys that may partly explain the paradox. For example, excess body fat is associated with early or exaggerated adrenarche and early pubertal development especially in girls. ${ }^{59-64}$ There was also an inverse association between HDL-C and exercise-induced change in FST, which suggests that children with higher HDL-C concentration had a more pronounced hyperemic reaction $(\triangle \mathrm{FST}=\mathrm{FST}$ before minus $\mathrm{FST}$ after) to exercise than others. We did not find a similar association between HDL-C and RI, suggesting that FST and RI may reflect somewhat different aspects of endothelial function.

The strengths of the present study include a relatively large population-based and well-defined study sample of both girls and boys. We studied not only SI but also RI and FST at rest and also the effect of a single bout of exercise on SI, RI and FST, which have rarely been reported in previous studies. We also included major potential confounding factors in the analyses. The main limitations of the study relate to the assessment of SI, RI and FST. We have previously reported a relatively good reproducibility for SI, RI and FST, but RI was more variable than others in the present study sample of children. ${ }^{23}$ There was some delay between the measurement of RI and FST after acute exercise due to the cooling-down period just after the exercise test and before the measurements, which could have attenuated the observed associations. Another limitation is that the calculated MetS score is sample specific, but the sample size was large and representative. Finally, we did not have an opportunity to investigate actual mechanisms contributing to changes in SI, RI and FST or to compare them to so-called gold-standard measures.

\section{Conclusions}

Metabolic risk factors were associated with arterial stiffness, tone and endothelial function, as measured by PCA and FST, among primary school children. These findings underscore the need for long-term follow-up studies to better understand the 
tracking of metabolic and vascular risk factors from childhood into adulthood and the role of lifestyle changes in the prevention of these risk factors.

\section{Acknowledgments}

We thank all members of the PANIC research group for making the study possible. The Physical Activity and Nutrition in Children (PANIC) Study has been supported by Finland's Ministry of Social Affairs and Health (1491/9.02.00/2009, 178/THL/TE/2010), Finland's Ministry of Education and Culture (121/627/2009), Finnish Cultural Foundation, Juho Vainio Foundation, Foundation for Paediatric Research, The Social Insurance Institution of Finland (22/26/2008), Finnish Innovation Fund Sitra and Annual EVO Financing (Special government subsidies, Kuopio University Hospital, 5031343). Conflicts of interest: None declared.

\section{References}

1. Yun JE, Won S, Sung J, Jee SH. Impact of metabolic syndrome independent of insulin resistance on the development of cardiovascular disease. Circ J 2012; 76: 2443-2448.

2. Saito I. Epidemiological evidence of type 2 diabetes mellitus, metabolic syndrome, and cardiovascular disease in Japan. Circ J 2012; 76: $1066-1073$.

3. Lim S, Despres JP, Koh KK. Prevention of atherosclerosis in overweight/obese patients: In need of novel multi-targeted approaches. Circ J 2011; 75: 1019-1027.

4. James PT, Rigby N, Leach R; International Obesity Task Force. The obesity epidemic, metabolic syndrome and future prevention strategies. Eur J Cardiovasc Prev Rehabil 2004; 11: $3-8$.

5. Saland JM. Update on the metabolic syndrome in children. Curr Opin Pediatr 2007; 19: 183-191.

6. Kavey RE, Daniels SR, Lauer RM, Atkins DL, Hayman LL, Taubert $\mathrm{K}$. American Heart Association guidelines for primary prevention of atherosclerotic cardiovascular disease beginning in childhood. Circulation 2003; 107: 1562-1566.

7. Steinberger J, Daniels SR, Eckel RH, Hayman L, Lustig RH, McCrindle B, et al. Progress and challenges in metabolic syndrome in children and adolescents: A scientific statement from the American Heart Association Atherosclerosis, Hypertension, and Obesity in the Young Committee of the Council on Cardiovascular Disease in the Young; Council on Cardiovascular Nursing; and Council on Nutrition, Physical Activity, and Metabolism. Circulation 2009; 119: $628-647$.

8. Iannuzzi A, Licenziati MR, Acampora C, Renis M, Agrusta M, Romano L, et al. Carotid artery stiffness in obese children with the metabolic syndrome. Am J Cardiol 2006; 97: 528-531.

9. Whincup PH, Gilg JA, Donald AE, Katterhorn M, Oliver C, Cook DG, et al. Arterial distensibility in adolescents: The influence of adiposity, the metabolic syndrome, and classic risk factors. Circulation 2005; 112: $1789-1797$.

10. Magnussen CG, Koskinen J, Chen W, Thomson R, Schmidt MD, Srinivasan SR, et al. Pediatric metabolic syndrome predicts adulthood metabolic syndrome, subclinical atherosclerosis, and type 2 diabetes mellitus but is no better than body mass index alone: The Bogalusa Heart Study and the Cardiovascular Risk in Young Finns Study. Circulation 2010; 16: 1604-1611.

11. Morrison JA, Friedman LA, Wang P, Glueck CJ. Metabolic syndrome in childhood predicts adult metabolic syndrome and type 2 diabetes mellitus 25 to 30 years later. J Pediatr 2008; 152: 201 - 206

12. Morrison JA, Friedman LA, Gray-McGuire C. Metabolic syndrome in childhood predicts adult cardiovascular disease 25 years later: The Princeton Lipid Research Clinics Follow-up Study. Pediatrics 2007; 120: $340-345$.

13. Ford ES, Li C. Defining the metabolic syndrome in children and adolescents: Will the real definition please stand up? J Pediatr 2008; 152: $160-164$

14. Ekelund U, Anderssen SA, Froberg K, Sardinha LB, Andersen LB, Brage S. Independent associations of physical activity and cardiorespiratory fitness with metabolic risk factors in children: The European youth heart study. Diabetologia 2007; 50: 1832-1840.

15. DuBose KD, Eisenmann JC, Donnelly JE. Aerobic fitness attenuates the metabolic syndrome score in normal-weight, at-risk-for-overweight, and overweight children. Pediatrics 2007; 120: e1262-e1268.

16. Millasseau SC, Kelly RP, Ritter JM, Chowienczyk PJ. Determination of age-related increases in large artery stiffness by digital pulse contour analysis. Clin Sci (Lond) 2002; 103: 371-377.

17. Chowienczyk PJ, Kelly RP, MacCallum H, Millasseau SC, Andersson TL, Gosling RG, et al. Photoplethysmographic assessment of pulse wave reflection: Blunted response to endothelium-dependent beta2adrenergic vasodilation in type II diabetes mellitus. J Am Coll Cardiol 1999; 34: 2007-2014.

18. Rambaran C, Jiang B, Ritter JM, Shah A, Kalra L, Chowienczyk PJ. Assessment of endothelial function: Comparison of the pulse wave response to beta 2-adrenoceptor stimulation with flow mediated dilatation. Br J Clin Pharmacol 2008; 65: 238-243.

19. Millasseau SC, Guigui FG, Kelly RP, Prasad K, Cockcroft JR, Ritter $\mathrm{JM}$, et al. Non-invasive assessment of the digital volume pulse: Comparison with the peripheral pressure pulse. Hypertension 2000; 36: 952-956.

20. Gul KM, Ahmadi N, Wang Z, Jamieson C, Nasir K, Metcalfe R, et al. Digital thermal monitoring of vascular function: A novel tool to improve cardiovascular risk assessment. Vasc Med 2009; 14: 143-148.

21. Xi B, Zhang L, Mi J. Reduced arterial compliance associated with metabolic syndrome in Chinese children and adolescents. Biomed Environ Sci 2010; 23: 102-107.

22. Munir S, Jiang B, Guilcher A, Brett S, Redwood S, Marber M, et al. Exercise reduces arterial pressure augmentation through vasodilation of muscular arteries in humans. Am J Physiol Heart Circ Physiol 2008; 294: H1645-H1650.

23. Veijalainen A, Tompuri T, Lakka HM, Laitinen T, Lakka TA. Reproducibility of pulse contour analysis in children before and after maximal exercise stress test: The Physical Activity and Nutrition in Children (PANIC) Study. Clin Physiol Funct Imaging 2011; 31: $132-138$.

24. Hale AR, Burch GE. The arteriovenous anastomoses and blood vessels of the human finger: Morphological and functional aspects. Medicine 1960; 39: 191-240.

25. Charkoudian N. Skin blood flow in adult human thermoregulation: How it works, when it does not, and why. Mayo Clin Proc 2003; 78: $603-612$.

26. Johnson JM. Physical training and the control of skin blood flow. Med Sci Sports Exerc 1998; 30: 382-396.

27. Wang JS. Effects of exercise training and detraining on cutaneous microvascular function in man: The regulatory role of endotheliumdependent dilation in skin vasculature. Eur J Appl Physiol 2005; 93: 429-434.

28. Viitasalo A, Laaksonen DE, Lindi V, Eloranta AM, Jääskeläinen J, Tompuri T, et al. Clustering of metabolic risk factors is associated with high-normal levels of liver enzymes among 6- to 8-year-old children: The PANIC Study. Metab Syndr Relat Disord 2012; 5: $337-343$.

29. The Northwest Institute for BioHealth Informatics. SDS Individual Calculator for British 1990 Growth Reference Data. http://www. phsim.man.ac.uk/SDSCalculator/ (accessed June 1, 2011).

30. Wijndaele K, Beunen G, Duvigneaud N, Matton L, Duquet W, Thomis M, et al. A continuous metabolic syndrome risk score: Utility for epidemiological analyses. Diabetes Care 2006; 29: 2329.

31. Okosun IS, Lyn R, Davis-Smith M, Eriksen M, Seale P. Validity of a continuous metabolic risk score as an index for modeling metabolic syndrome in adolescents. Ann Epidemiol 2010; 20: 843-851.

32. Kahn R, Buse J, Ferrannini E, Stern M. The metabolic syndrome: Time for a critical appraisal: Joint statement from the American Diabetes Association and the European Association for the Study of Diabetes. Diabetes Care 2005; 28: 2289-2304.

33. Thivel D, Malina RM, Isacco L, Aucouturier J, Meyer M, Duché P. Metabolic syndrome in obese children and adolescents: Dichotomous or continuous? Metab Syndr Relat Disord 2009; 7: 549-555.

34. Ragland DR. Dichotomizing continuous outcome variables: Dependence of the magnitude of association and statistical power of the cutpoint. Epidemiology 1992; 3: 434-440.

35. Eisenmann JC, Laurson KR, DuBose KD, Smith BK, Donnelly JE. Construct validity of a continuous metabolic syndrome score in children. Diabetol Metab Syndr 2010; 2: 8.

36. Eisenmann JC. On the use of a continuous metabolic syndrome score in pediatric research. Cardiovasc Diabetol 2008; 7: 17.

37. Cole TJ, Bellizzi MC, Flegal KM, Dietz WH. Establishing a standard definition for child overweight and obesity worldwide: International survey. BMJ 2000; 320: 1240-1243.

38. Cook S, Auinger P, Huang TT. Growth curves for cardio-metabolic risk factors in children and adolescents. J Pediatr 2009; 155: S6.e15S6.e26.

39. National High Blood Pressure Education Program Working Group on High Blood Pressure in Children and Adolescents. The fourth report on the diagnosis, evaluation, and treatment of high blood pressure in children and adolescents. Pediatrics 2004; 114: 555-576.

40. Reinehr T, de Sousa G, Toschke AM, Andler W. Comparison of metabolic syndrome prevalence using eight different definitions: A critical approach. Arch Dis Child 2007; 92: 1067-1072. 
41. Brillante DG, O'Sullivan AJ, Howes LG. Arterial stiffness indices in healthy volunteers using non-invasive digital photoplethysmography. Blood Press 2008; 2: 116-123.

42. Bornmyr S, Svensson H, Lilja B, Sundkvist G. Skin temperature changes and changes in skin blood flow monitored with laser Doppler flowmetry and imaging: A methodological study in normal humans. Clin Physiol 1997; 17: 71-81.

43. Mirbod SM, Yoshida H, Jamali M, Miyashita K, Takada H, Inaba R, et al. Finger skin temperature and laser-Doppler finger blood flow in subjects exposed to hand-arm vibration. Ind Health 1998; 36: 171 178 .

44. Bornmyr S, Svensson H, Söderström T, Sundkvist G, Wollmer P. Finger skin blood flow in response to indirect cooling in normal subjects and in patients before and after sympathectomy. Clin Physiol 1998; 18: 103-107.

45. Scholze A, Burkert A, Mardanzai K, Suvd-Erdene S, Hausberg M, Zidek W, et al. Increased arterial vascular tone during the night in patients with essential hypertension. J Hum Hypertens 2007; 21: 60-67.

46. Savastano DM, Gorbach AM, Eden HS, Brady SM, Reynolds JC, Yanovski JA. Adiposity and human regional body temperature. $\mathrm{Am}$ J Clin Nutr 2009; 90: 1124-1131.

47. Verlohren S, Dubrovska G, Tsang SY, Essin K, Luft FC, Huang Y, et al. Visceral periadventitial adipose tissue regulates arterial tone of mesenteric arteries. Hypertension 2004; 44: 271-276.

48. Fernández-Alfonso MS. Regulation of vascular tone: The fat connection. Hypertension 2004; 44: 255-256.

49. Davis MJ, Hill MA. Signaling mechanisms underlying the vascular myogenic response. Physiol Rev 1999; 79: 387-423.

50. Vallance P, Chan N. Endothelial function and nitric oxide: Clinical relevance. Heart 2001; 85: 342-350.

51. Akata T. General anesthetics and vascular smooth muscle: Direct actions of general anesthetics on cellular mechanisms regulating vascular tone. Anesthesiology 2007; 106: 365-391.

52. Halliwill JR. Mechanisms and clinical implications of post-exercise hypotension in humans. Exerc Sport Sci Rev 2001; 29: 65-70.

53. Haram PM, Adams V, Kemi OJ, Brubakk AO, Hambrecht R, Ellingsen $\mathrm{O}$, et al. Time-course of endothelial adaptation following acute and regular exercise Eur J Cardiovasc Prev Rehabil 2006; 13: 585-591.

54. Gilligan DM, Panza JA, Kilcoyne CM, Waclawiw MA, Casino PR, Quyyumi AA. Contribution of endothelium-derived nitric oxide to exercise-induced vasodilation. Circulation 1994; 90: 2853-2858.

55. Padilla J, Harris RA, Wallace JP. Can the measurement of brachial artery flow-mediated dilation be applied to the acute exercise model? Cardiovasc Ultrasound 2007; 5: 45.

56. Goto C, Nishioka K, Umemura T, Jitsuiki D, Sakagutchi A, Kawamura $\mathrm{M}$, et al. Acute moderate-intensity exercise induces vasodilation through an increase in nitric oxide bioavailability in humans. Am J Hypertens 2007; 20: 825-830.

57. Lteif AA, Han K, Mather KJ. Obesity, insulin resistance, and the metabolic syndrome: Determinants of endothelial dysfunction in whites and blacks. Circulation 2005; 5: 32-38.

58. Lind L. Endothelium-dependent vasodilation, insulin resistance and the metabolic syndrome in an elderly cohort: The Prospective Investigation of the Vasculature in Uppsala Seniors (PIVUS) study. Atherosclerosis 2008; 196: 795-802.

59. Perregaux D, Chaudhuri A, Mohanty P, Bukhari L, Wilson MF, Sung $\mathrm{BH}$, et al. Effect of gender differences and estrogen replacement therapy on vascular reactivity. Metabolism 1999; 48: 227-232.

60. Klein KO, Baron J, Colli MJ, McDonnell DP, Cutler GB Jr. Estrogen levels in childhood determined by an ultrasensitive recombinant cell bioassay. J Clin Invest 1994; 94: 2475-2480.

61. Baer HJ, Colditz GA, Willett WC, Dorgan JF. Adiposity and sex hormones in girls. Cancer Epidemiol Biomarkers Prev 2007; 16: $1880-1888$.

62. Sader MA, Celermajer DS. Endothelial function, vascular reactivity and gender differences in the cardiovascular system. Cardiovasc Res 2002; 53: 597-604.

63. Biro FM, Khoury P, Morrison JA. Influence of obesity on timing of puberty. Int J Androl 2006; 29: 272-277.

64. Utriainen P, Jääskeläinen J, Romppanen J, Voutilainen R. Childhood metabolic syndrome and its components in premature adrenarche. $J$ Clin Endocrinol Metab 2007; 92: 4282-4285.

\section{Supplementary Files}

Supplementary File 1

Figure S1. The means of (A) stiffness index, (B) reflection index and (C) finger skin temperature in groups of different components of metabolic syndrome according to modified definitions together with $\mathrm{P}$-value when compared to those that did not cross the cut point of component at issue.

Figure S2. The means of (A) stiffness index, (B) reflection index and (C) finger skin temperature in groups of different components of metabolic syndrome according to pediatric definitions together with P-value when compared to those that did not cross the cut point of component at issue.

Figure S3. The means of (A) stiffness index and (B) reflection index (RI) and finger skin temperature (FST) in groups of clustering of components (comp.) of metabolic syndrome (MetS) according to pediatric definitions together with P-value when compared to those having no features of MetS.

Table S1. Relation of Dichotomized Variables of MetS and Its Components to Exercise Induced Change in RI and FST Together With Statistically Significant Gender Differences According to (A) Modified- and (B) Pediatric Definitions

Please find supplementary file(s);

http://dx.doi.org/10.1253/circj.CJ-12-0704 